\title{
Resiliencia y pandemia: experiencias y relatos
}

\author{
Resilience and pandemic: experiences and stories
}

\section{Resiliência e pandemia: experiências e relatos}

\section{Anna María Fernández Poncela*}

\begin{abstract}
RESUMEN
Varios estudios presentan los impactos psicológicos de la pandemia y las medidas tomadas para enfrentarla, así como sus consecuencias en las personas. Aquí se realiza un acercamiento inicial y exploratorio a la resiliencia de las personas a través de datos generales y de contexto de encuestas para México y, muy especialmente, relatos de experiencias en entrevistas a un grupo de personas en la capital del país.
\end{abstract}

\begin{abstract}
Several studies present the pandemic's psychological impacts, the measures taken to deal with it, and its consequences on individuals. Here we make an initial and exploratory approach to people's resilience through general and contextual data from surveys in Mexico and, most significantly, accounts of experiences in interviews with a group of people in the country's capital city.
\end{abstract}

\section{RESUMO}

Vários estudos apresentam o impacto psicológico da pandemia e das medidas tomadas para enfrentá-la, assim como suas consequências nas pessoas. Aqui é realizada uma abordagem inicial e exploratória da resiliência das pessoas, através de dados gerais e de contexto de pesquisas realizadas no México e,
Palabras clave: experiencias, impactos psicológicos, medidas sanitarias, pandemia, resiliencia.

\section{Keywords:} experiences, psychological impacts, health measures, pandemic, resilience.

Palavras-chave: experiências, impacto psicológico, medidas sanitárias, pandemia, resiliência.

\footnotetext{
* Mexicana. Doctora en Antropología, Universidad de Barcelona, maestría en Sociología. Profesora e investigadora de la Universidad Autónoma Metropolitana. Ciudad de México, México.fpam1721@correp.xoc.uam.mx
} 
Resiliencia y pandemia: experiencias y relatos | Fernández

de maneira muito especial, mediante relatos de experiências em entrevistas com um grupo de pessoas na capital do país. 


\title{
Introducción
}

\author{
"Hasta el presente, los investigadores han enfocado los estragos \\ indiscutibles, ahora hay que emprender la búsqueda de procesos de \\ recuperación". (Cyrulnic, 2007, p. 17)
}

En los últimos años ha cobrado auge el término resiliencia en el campo de la psicología, desde que Boris Cyrulnik lo divulgó por todo el mundo a finales del siglo XX, inspirado en los textos de John Bowlby. Hay momentos en la existencia de las personas o en la historia de la humanidad donde dicho concepto y su puesta en práctica cobra importancia, como es en la coyuntura de la pandemia COVID-19 de 2020 y, particularmente, las consecuencias sociales y psicológicas de las medidas tomadas por la Organización Mundial de la Salud (OMS) y los gobiernos de los países.

La hipótesis que guía esta investigación es que tras la sorpresa y asombro inicial luego de la declaración de pandemia internacional el 11 de marzo de 2020 - el anuncio de China el 11 de enero y la alerta de la OMS el 11 de febrero-, y la aplicación de las medidas tomadas por el gobierno mexicano a finales de ese mismo mes, en medio de la incertidumbre y el miedo la población se adaptó de forma resiliente a la situación y a sus consecuencias psicológicas y económicas, personales y colectivas. El objetivo fue investigar, comprobar y mostrar que la población o un grupo de la misma, desarrolló un proceso de resiliencia en medio de la disrupción de la pandemia y sus efectos. En concreto se pasó revista a los estilos, estrategias y acciones o actividades de afrontamiento resiliente y no resiliente a través de testimonios de la ciudadanía respecto del tema. No se aborda la pandemia misma ni la parte sanitaria o política, sino que este trabajo se centra en buscar y describir los pensamientos, sentimientos, actitudes y acciones resilientes llevadas a cabo por las personas en el contexto de la contingencia sanitaria.

Como afirma un reciente texto de la Organización Panamericana de la Salud (OPS, 2020, p. 1) al respecto "el aislamiento social forzoso al que nos hemos visto abocados por la pandemia del COVID-19, pone a prueba nuestras habilidades emocionales, cognoscitivas y socioafectivas". En pocos días no solo hubo en general un cambio radical en el estilo de vida para todo el mundo producto de un evento disruptivo a escala global, 
sino que en el sistema escolar la comunidad educativa fue sometida a medidas extremas obligatorias, a lo cual se respondió con un tsunami de estrategias de rápida adecuación (Román et al., 2020). Lo mismo aconteció en otros sectores laborales donde el trabajo en casa (homeoffice) se convirtió en la nueva modalidad laboral, con el estrés que también esto comporta. El desempleo, la reducción de ingresos en ciertos grupos también hizo importante mella. Y para todo mundo el caudal de noticias en tono alarmante y constante, también impactó como los medios saben y suelen hacer (Costa, 2011). Sin olvidar "Su sana distancia" y "Quédate en casa”, como campañas centrales por esos días, el uso del gel antibacterial y el tapabocas. En fin, un panorama colmado de incertidumbre por no decir de terror, desde ciertos organismos y medios. En el caso de México, si bien el tono de las autoridades fue menos alarmista y las medidas algo menos duras punitivamente hablando, no por ello la confusión dejó de reinar durante meses en las mentes de la población, especialmente embargada por el miedo, como más adelante se mostrará. Ante ello, se desplegaron diversas capacidades de resiliencia, motivo que dio origen al presente artículo.

Se parte también de la concepción de que "aparte de situaciones extremas hay también una resiliencia muy presente en la vida diaria de la gran mayoría de las personas, pero menos espectacular y, por tanto, menos visible, menos documentada" (Vanistendael, 2010, p. 227). En ese sentido, es en la vida cotidiana donde tiene lugar el proceso adaptativo para la sobrevivencia, seguir adelante y la recuperación. Y es que en un mundo poco claro, con noticias impactantes, incertidumbre, y medidas poco habituales, la resiliencia es más que necesaria: es primordial.

\section{Resiliencia: una definición conceptual}

"La resiliencia es la habilidad de saber construirse, en cada ocasión, un entorno efectivamente seguro desde el cual explorar el mundo".

(Grané y Forés, 2012, p.10)

Sobre el significado, según el diccionario de la Real Academia Española (RAE) (s.f.) la resiliencia se trata de una capacidad de adaptación ante un agente perturbador o de una situación adversa, aplicándose para todo ser vivo. Sin ser exhaustivos, se presenta a continuación un resumen de lo que quieren decir este concepto y su práctica, con objeto de enmarcar el estudio empírico que se realizó. 
La resiliencia se considera como la capacidad de una persona o de un colectivo para sobrellevar o superar situaciones y momentos traumáticos en su vida, anteponerse a las circunstancias adversas cotidianas de la existencia, o bien, a ciertos traumas en la misma, e incluso con resultados favorables o positivos. Dicha capacidad permite desplegar pensamientos, sentimientos y conductas adecuadas y satisfactorias frente a amenazas, conflicto o estrés. Con ello, se desarrolla la habilidad de sortear y dejar atrás problemas, limitaciones y obstáculos hasta grandes tragedias, de modo de afrontar constructiva y saludablemente las adversidades y sobreponerse a ellas.

Cabe subrayar también que la resiliencia se trata de un proceso y no de una cualidad, en el sentido que se va construyendo con las variables culturales, familiares, ambientales, además de las personales, y que es evidentemente dinámico y contextual, con lo cual se remarca la oportunidad de crecimiento que conlleva, por las estrategias de ajuste y de afrontamiento. De hecho, se afirma que:

frente a la "resiliencia clásica" que se refiere a la capacidad de un grupo o de una persona de afrontar, sobreponerse a las adversidades y resurgir fortalecido o transformado. La segunda, la "resiliencia generativa" se vincula con la virtud de generar opciones, metamorfosis y seguir viviendo. La resiliencia generativa permite experimentar la adversidad como una oportunidad de crecimiento y desarrollo. (Román et al., 2020, p. 78).

Por su parte, para que el proceso de resiliencia tenga lugar debe conjuntar o entretejer los aspectos neurológicos, los afectivos y los culturales (Cyrulnik, 2010). Finalmente, si pensamos en el conflicto, desde la psicología se considera a la resiliencia como una fuente de crecimiento (Simmel, 2010).

Respecto de las características de las personas resilientes, estas no intentan tener todo bajo control, poseen sentido del humor, aprecian la calma y el silencio y hacen ejercicio. En general, se trata de personas con metas, capacidad de solución de problemas, que se cuidan, cultivan el optimismo, aceptan el cambio, tienen una amplia red social, creen en sí mismas y sus habilidades, y poseen un sentido y propósito de vida (Frankl, 2003), a partir de nociones tendientes a la resolución de problemas, el equilibrio emocional, y las relaciones contenedoras, entre otras (Manrique y Vidal, 2006). 
Ahora bien, con el objetivo de optimizar la presentación de testimonios, se elaboró una tabla clasificatoria que reúne indicadores, según la bibliografía disponible acerca del tema y el previo análisis de entrevistas, con lo que se espera dar coherencia a las experiencias narradas desde el significado de ser resiliente.

En relación con las estrategias y actividades de afrontamiento, se considera que hay ciertos estilos y estrategias de afrontamiento que, a su vez, se combinan con acciones individuales, familiares y sociales (Frydenberg citado Manrique y Vidal, 2006).

Para efectos prácticos, se ha elaborado la Tabla 1 que consigna, a modo de enumeración resumida, e estilos, estrategias y actividades resilientes, así como las capacidades de afrontamiento adaptativas (resiliencia) y no adaptativas (no resiliencia), es decir, aproximación (afrontamiento resiliente efectivo, adaptativo y protector) y evitación (evasión, negación). Lógicamente, en cada uno de estos comportamientos influyen los recursos internos - las características de personalidad-y los externos, los factores contextuales como la cultura, el territorio y el ambiente; los factores mediadores (riesgo, protección) y la especialidad de resistencia y transformación, o sea, la resiliencia (OPS, 2020). A la luz de esto, se debe recordar que existen varios estilos de afrontamiento, como el centrado en los problemas y el que está focalizado en la emoción, incluyendo la cognición y el comportamiento (Lazarus y Folkman, 1986). En cuanto a las estrategias, hay gran variedad de ellas según obras y autores, por lo que aquí se retoman aquellas consideradas más importantes y destacadas, además de aplicables al estudio de caso desarrollado y expuesto. Según la OPS (2020), las estrategias son individuales, familiares, sociales. Por otra parte, si la resiliencia es la capacidad de desarrollar el potencial humano tras la superación de las circunstancias traumáticas, las estrategias de afrontamiento son múltiples, algunas apuntan a una mayor resiliencia y otras mantienen la vulnerabilidad (Morán et al., 2019). Por ello, se han elaborado varios instrumentos cuantitativos para enumerarlas - afrontamiento activo, planificación, apoyo instrumental, apoyo económico, autodistracción, desahogo, desconexión, reinterpretación positiva, negación, aceptación, religión, uso 
de sustancias, humor y auto inculpación (COPE citado en Morán et al., 2010). ${ }^{1}$

Tabla 1

Estilos, estrategias y actividades de afrontamiento resilientes y no resilientes

\begin{tabular}{|c|c|c|}
\hline Estilos & Estrategias & Actividades \\
\hline $\begin{array}{l}\text { Resolver } \\
\text { problemas, } \\
\text { actuar. }\end{array}$ & $\begin{array}{l}\text { Concentrarse en resolver } \\
\text { problemas a través de } \\
\text { acciones, para solucionar } \\
\text { o modificar el problema, o } \\
\text { en su caso, actuar de alguna } \\
\text { manera. } \\
\text { Esfuerzo para manejar } \\
\text { situaciones. Afrontamiento } \\
\text { activo. }\end{array}$ & $\begin{array}{l}\text { Dedicación al tema, planificar } \\
\text { soluciones, reorientar metas. } \\
\text { Trabajar. } \\
\text { Divertirse, distraerse, } \\
\text { autodistraerse. } \\
\text { Hobbies, pasatiempos, ocio, } \\
\text { pintar, leer, cine, música, } \\
\text { juegos. } \\
\text { Descansar. } \\
\text { Ejercicio físico. } \\
\text { Dieta adecuada. } \\
\text { Respirar bien. } \\
\text { Tareas domésticas y arreglos } \\
\text { en el hogar. } \\
\text { Pendientes o proyectos } \\
\text { postergados. } \\
\text { Aprendizajes varios. }\end{array}$ \\
\hline $\begin{array}{l}\text { Equilibrar } \\
\text { emociones, } \\
\text { actuar. }\end{array}$ & $\begin{array}{l}\text { Concentrarse en manejar las } \\
\text { emociones y liberar estrés } \\
\text { u otras emociones dañinas, } \\
\text { sentirlas, expresarlas, } \\
\text { trabajarlas. } \\
\text { Focalizar en aprender a } \\
\text { aprender y desarrollar } \\
\text { capacidades cognitivas. } \\
\text { Esfuerzo adaptativo. } \\
\text { Apoyo emocional. } \\
\text { Aceptación. } \\
\text { Reinterpretación positiva, } \\
\text { creer que la persona } \\
\text { influencia lo que acontece. }\end{array}$ & $\begin{array}{l}\text { Focalizar lo positivo en } \\
\text { general. } \\
\text { Diversiones. } \\
\text { Expresar lo que se siente, } \\
\text { desahogo. } \\
\text { Manifestar y demostrar } \\
\text { afecto. } \\
\text { Conversar. } \\
\text { Relajación, visualización, } \\
\text { meditación. } \\
\text { Mundo espiritual, religión, } \\
\text { oración. } \\
\text { Aceptación del cambio, } \\
\text { realista y flexible. } \\
\text { Capacidad continua de } \\
\text { aprendizaje, competencias } \\
\text { cognitivas. } \\
\text { Capacidad de adaptación, } \\
\text { creatividad, decisión, } \\
\text { iniciativa, interacción, } \\
\text { perseverancia. }\end{array}$ \\
\hline
\end{tabular}

1 Desde ciertos enfoques psicológicos hay diferentes cuestionarios cuantitativos con objeto de formular ítems y hacer inventario y evaluación multidimensional de las diferentes respuestas al estrés, como el Brief COPE de Caver (citado Morán el al., 2010). 


\begin{tabular}{|c|c|c|}
\hline & & $\begin{array}{l}\text { Autoconocimiento, } \\
\text { autoestima, autoconfianza, } \\
\text { autocrítica. } \\
\text { Equilibrio emocional o } \\
\text { gestión emocional. } \\
\text { Actitud positiva, optimismo, } \\
\text { asertividad. } \\
\text { Responsabilidad, autonomía, } \\
\text { independencia. } \\
\text { Empatía, comprensión, } \\
\text { compromiso, simpatía. } \\
\text { Tolerancia a la incertidumbre } \\
\text { y la frustración, paciencia, } \\
\text { flexibilidad. } \\
\text { Crisis como oportunidad. } \\
\text { Sentido y propósito de vida, } \\
\text { motivación. } \\
\text { Sentido del humor, sonreír. }\end{array}$ \\
\hline $\begin{array}{l}\text { Relación con } \\
\text { los otros, } \\
\text { actuar. }\end{array}$ & $\begin{array}{l}\text { Invertir en las relaciones } \\
\text { sociales, redes, instituciones, } \\
\text { familia, apoyos de otras } \\
\text { personas para reducir estrés. } \\
\text { Amplia y consolidada red de } \\
\text { relaciones sociales positivas } \\
\text { de apoyo: familia, amistades. }\end{array}$ & $\begin{array}{l}\text { Sociabilidad. } \\
\text { Ayuda profesional, ayuda } \\
\text { emocional y consejo. } \\
\text { Ayuda de familia, amistades, } \\
\text { expresar, escuchar, compartir } \\
\text { Grupos de apoyo social, } \\
\text { pertenencia. } \\
\text { Pertenencia, cohesión social, } \\
\text { acción social. } \\
\text { Activismo, reflexión social. } \\
\text { Ayudando a otras personas } \\
\text { vulnerables. } \\
\text { Mejorar relaciones con los } \\
\text { demás. } \\
\text { Mejora institucional. }\end{array}$ \\
\hline $\begin{array}{l}\text { Afrontamiento } \\
\text { no productivo }\end{array}$ & $\begin{array}{l}\text { Desconocer o evitar el } \\
\text { problema, aplazar o negar. } \\
\text { Disociación, negación. } \\
\text { Aplazar afrontamiento. } \\
\text { Desconexión. }\end{array}$ & $\begin{array}{l}\text { Esperar un milagro, hacerse } \\
\text { ilusiones. } \\
\text { Preocuparse. } \\
\text { Auto inculparse, criticarse, } \\
\text { culpabilizarse. } \\
\text { No expresar. } \\
\text { Temor al futuro. } \\
\text { Ignorar, negar, evadir } \\
\text { Renunciar. } \\
\text { Consumir sustancias } \\
\text { (medicamentos, alcohol, } \\
\text { cigarrillos, drogas). }\end{array}$ \\
\hline
\end{tabular}

Fuente: Elaboración propia sobre la base de Lazarus y Folkman (1986); Levine y Frederick (1996); Manrique y Vidal (2006), Morán et al. (2010); Morán et al. (2019) y OPS (2020). 
Complementariamente, el equilibrio de las emociones y las relaciones satisfactorias son centrales en la psicología positiva, la que busca la felicidad primero y el bienestar después (Seligman, 2011; 2014). Desde este enfoque, entonces, el optimismo es una fortaleza de carácter (Avia y Vázquez, 2011), que puede ayudarnos a sentir más fuertes y capaces al momento de afrontar situaciones adversas como un trauma personal o un desastre colectivo, cuando las personas se hunden o salen a flote, y en donde los cambios pueden representar una oportunidad para resolver, aprender a superar y regresar a la vida con sentido (O'Hanton, 2005). Así mismo, los seres humanos poseen la innata capacidad para sanarse a sí mismos y al mundo de los efectos del trauma, incluso de los sociales y culturales (Levine y Frederick, 1996). Existe una habilidad natural de afrontar y resistir, aprender y crecerse en la adversidad, lo que se ha dado en llamar crecimiento postraumático o aprendizaje a través el proceso de lucha (Vera et al., 2006). ${ }^{2}$

\section{Metodología}

Esta investigación se centra en la resiliencia en la pandemia y se conforma a partir de la revisión bibliográfica y documental usual, el seguimiento de las noticias en la prensa, y de forma especial en las encuestas publicadas en torno al tema en México a lo largo del año 2020 e inicios del 2021, fuentes que aportan el contexto socioemocional de la población.

Se parte de un enfoque fenomenológico hermenéutico en el sentido que tiene lugar la descripción, comprensión, explicación e interpretación de la esencia de las experiencias vividas, buscando la conciencia y los significados en torno al tema estudiado (Fuster, 2019). Al respecto, la fenomenología se refiere a cómo los seres humanos comprenden los significados de la experiencia desde su propia lógica (Schütz, 2008), en tanto que la hermenéutica apunta a comprender al otro a través de lo dicho y sus significados. Con ello, se espera dar lugar a una suerte de comprensión interpretativa de la experiencia y sus significados, por supuesto, a través del punto de vista de la persona.

2 Todo lo cual no significa que todas las personas libren las adversidades, y no haya quien persista en el malestar o la patología. Así como no siempre una circunstancia negativa provoca conflicto, esto acontece cuando se percibe y valora más allá de las habilidades de afrontamiento. 
El diseño de investigación consideró un diseño estructurado y uno emergente, con flexibilidad (Valles, 1997), donde hubo lugar para el empleo del método cualitativo y la técnica de entrevista la que - como herramienta de excavar o una forma de viajar-, construye información de manera rica, significativa y profunda desde la voz y mirada de quien participa, o sea, desde la perspectiva de las y los actores, sin desconocer la intervención de quien investiga y remarcando la espiral autorreflexiva que puede provocar (Denzin y Lincoln, 2012; Fernández, 2009; Gubern, 2012).

De forma particular, a finales de 2020, en diciembre, se contó con la aplicación de 30 entrevistas a un grupo de personas pertenecientes a distintos sectores sociales de la Ciudad de México. Por ello, se trata de un estudio de caso instrumental sin buscar representación estadística, sino más bien explicación comprensiva (Stake, 1994; Yin, 1981). En concreto, fueron 19 mujeres y 11 hombres, de diferentes Alcaldías políticas del sur de la Ciudad de México y de diversas edades — de 18 a 68 años- y sectores sociales. En este sentido es un muestreo intencional y oportunista (Verd y Lozares, 2016), eligiendo a las personas, en principio según sexo y edad y lugar de residencia, aunque en la práctica se aplicó la entrevista a quien accedió a ser entrevistado, debido a la poca receptividad a la propuesta hallada en esos momentos. Al acercarse a la cifra de 30 entrevistas ya se encontró cierta saturación, por lo que este fue el número final seleccionado.

Debido a las circunstancias de distanciamiento social, las entrevistas se aplicaron algunas presenciales y otras vía zoom o videollamada de WhatsApp. Igualmente fue más difícil acceder a la población masculina y de mayor edad, de ahí que más mujeres y jóvenes constituyen la muestra, pues fueron más receptivas y accesibles (Tabla 2$)^{3}$.

3 Cada fragmento presentado se acompaña del sexo, edad, ocupación y lugar de residencia de la persona que participó con su testimonio, con objeto de tener sus datos en cada momento. 
Tabla 2

Muestra de entrevistas en Ciudad de México (diciembre 2020)

\begin{tabular}{lccc}
\hline & Mujer & Hombre & Total \\
\hline Alcaldía & $\mathrm{N}$ & $\mathrm{N}$ & $\mathrm{N}$ \\
\hline Tlalpan & 4 & -- & 4 \\
\hline Coyoacán & 2 & 1 & 3 \\
\hline Gustavo Madero & 2 & -- & 2 \\
\hline Álvaro Obregón & -- & 1 & 1 \\
\hline Xochimilco & 4 & 4 & 8 \\
\hline Tláhuac & 1 & -- & 1 \\
\hline Iztapalapa & 1 & -- & 1 \\
\hline Milpa Alta & 5 & 5 & 10 \\
\hline Total & 19 & 11 & 30 \\
\hline
\end{tabular}

El cuestionario constó de 60 interrogantes que giraron en torno a cómo se sentían las personas en relación con la pandemia, con baterías de preguntas directas respecto de emociones; orígenes; gravedad; actuación gubernamental; quehacer personal, familiar y socialmente; situación personal pasada, presente y futura; cambios; lo mejor y lo peor, etc. Para los efectos de este trabajo solo se retomaron las partes relacionadas con la resiliencia que aparecen expresadas a lo largo de las entrevistas. Ello aporta información a través de testimonios de primera mano con opiniones, emociones, experiencias y valoraciones de lo vivido. Cabe advertir que se trató de una investigación acerca del estado de ánimo, las actitudes, y entre otras cosas, de la resiliencia; no obstante, varios de los relatos aparecieron tocando el tema de soslayo o directamente, enunciando un testimonio del mismo, por lo que aquí se trabajaron las ideas y prácticas de esta capacidad y proceso personal y colectivo, con el objeto de ilustrar su presencia en esos días. Por otra parte, en un afán de ordenar los relatos, estos se clasificaron por indicadores de categorías de estilo, estrategias y acciones de resiliencia, aun cuando a veces una misma transcripción reflejaba varios aspectos.

La investigación se trató de un diseño narrativo de obtención de relatos testimoniales (Bruner, 2002; Creswell, 2005) la que a través de la entrevista perseguía recabar experiencias y significados, según lo que dice el discurso y contenido del texto (Verd y Lozares, 2016). 
A la hora del análisis, las categorías se elaboraron con base en varios autores y propuestas, las que colaboraron en ordenar y clasificar los testimonios, cobrando su sentido más allá de sí mismos, entretejiendo significados que trascendieron las palabras. Su elaboración se realizó a través de la inspiración teórica y de la revisión práctica, detallada y profunda de las narraciones obtenidas en las respuestas de las entrevistas, según la teoría fundamentada que genera un diálogo entre teoría y datos (Glaser y Strauss, 1967; Strauss y Corbin, 2002). ${ }^{4}$

\section{Resultados}

Los impactos en México: datos del miedo y relatos de la resiliencia

"La resiliencia es más que resistir, es también aprender a vivir". (Cyrulnik, 2007, p. 191)

Para acercarnos al contexto mexicano se presentan algunos datos que muestran el clima social emocional de la gente a lo largo de 2020 en relación con la pandemia y la economía, dos preocupaciones presentes y constantes que enmarcan las diversas actitudes resilientes que testimonian las personas según sus vivencias y sentires, y que se presentan en un apartado posterior.

\section{Algunos acercamientos a los efectos psicológicos en el mundo}

"Resiliencia: Capacidad de adaptación de un ser vivo frente a un agente perturbador o un estado o situación adversos".(RAE, 2020)

En cuanto a los impactos psicológicos, ya se cuenta con estudios para China, India, Argentina, Colombia, Uruguay, España y México, y seguramente para más países (Sandín, et al., 2020). En este artículo se trabajó el caso de México, con un enfoque inicial y exploratorio a través de la revisión de entrevistas y características de resiliencia, esto es, estrategias y actividades que denotan pensamientos, sentimientos $\mathrm{y}$ acciones resilientes en las personas.

4 En concreto, la segmentación de entrevistas según ejes temáticos, la conceptualización y clasificación con codificación abierta, la vinculación de categorías según codificación axial, el análisis de lo obtenido por ejes temáticos y la síntesis (Strauss y Corbin, 2002). 
En el contexto internacional, se ha afirmado que México es uno de los países con menor resiliencia en un ranking que se realizó en el año 2020, lo que resulta paradojal si se considera que tradicionalmente México se ha reconocido como uno de los países más felices del mundo (Forbes, 2019) y que la resiliencia favorece, precisamente, la felicidad.

Los titulares afirmaron: "México, el peor país para vivir durante la pandemia de COVID-19, según ranking de Bloomberg" (El Financiero, $2020)^{5}$ y "México es el peor país para vivir en tiempos de COVID-19; con la tasa de mortalidad más alta de 53 países" (El Economista, 2020) ${ }^{6}$. Tanto los reportajes como el estudio internacional que presentaron estas fuentes muestran la similitud ideológica en el intento de desacreditar la política del gobierno de México ante la pandemia, pero lo que aquí interesa es el término de resiliencia y su empleo, el que últimamente se ha extendido a diversos ámbitos sociales, más allá de la psicología donde tuvo su nacimiento, aunque en honor a la verdad es

5 “El Ranking de Resiliencia COVID puntúa economías de más de 200 mil millones de dólares en diez métricas clave: desde el crecimiento de los casos de virus hasta la tasa de mortalidad general, las capacidades de prueba y los acuerdos de suministro de vacunas que los lugares han forjado. También se tiene en cuenta la capacidad del sistema sanitario local, el impacto de las restricciones relacionadas con el coronavirus, los bloqueos económicos, y la libertad de circulación de los ciudadanos. El resultado es un puntaje general que es una especie de fotografía instantánea de cómo se está desarrollando la pandemia en estos 53 lugares en este momento". (El Financiero, 2020)

6 "En conjunto, las medidas sanitarias en relación con las restricciones a la movilidad no han logrado impactar de manera significativa en la contención del virus. El ranking indica que México tiene bajos resultados en términos de detección y tratamiento del virus. Por un lado, la tasa de positividad promedio es de $62,3 \%$; lo que implica que más de la mitad de quienes se realizan la prueba para detectar si tienen COVID-19, efectivamente portan el virus. En el análisis realizado por Bloomberg se destaca que una de las prácticas que llevó a los países a tener mejores niveles de resiliencia fue la aplicación masiva y temprana de pruebas COVID-19, rastreo de casos y realización de cuarentenas. Esto en términos de prevención y detección. En la otra parte del proceso, si bien para la población total mexicana el número de contagios no es el mayor a escala global, la tasa de mortalidad sí es de las más altas. De hecho, en el ranking México ocupa el primer lugar: $8,6 \%$ de los pacientes que contrae el virus, fallece a causa de este. En este sentido se pueden desagregar factores múltiples, desde la capacidad previa del sistema de salud, el desarrollo científico de efectividad en tratamientos y hasta la persistencia de comorbilidades entre la población. Otro de los indicadores en foco es el total de decesos por cada millón de habitantes (en el país esta tasa es de 782 por millón). El factor político-social también tiene importancia. El análisis mostró que en los países donde la paralización económica y de movilidad fue más relajada y aún así han logrado contener el virus tiene una relación directa con la percepción de la población de confianza en las autoridades y en el cumplimiento del gobierno. Los ejemplos de este método son Japón, Corea y Suecia" (El Economista, 2020). 
un concepto que viene de la física y la capacidad de los materiales para recuperar su estado inicial tras una perturbación (RAE, 2020). Al respecto, cabe reiterar que en otras ocasiones México ha sido titular por ser uno de los países más felices del planeta. Justo un año antes de la pandemia Forbes (2019) afirmaba: "México, el segundo país más feliz del mundo: Happy Planet Index". No obstante lo anterior, más adelante se verá con la exposición de experiencias particulares de los sujetos de estudio, que sí hubo resiliencia y de manera más que importante. Esto probaría que muchas veces las noticias, los discursos y la investigación oficial van por un lado, y la percepción y experiencia de la realidad cotidiana por parte de la ciudadanía camina en otro sentido.

\section{El miedo en México: panorama general y contextual emocional}

Según los datos de las encuestas nacionales revisadas (entre febrero de 2020 y febrero del 2021), el miedo ha aumentado de forma considerable entre la población en general, o más concretamente, aumentaron los miedos asociados al contagio propio, de un familiar y a la muerte. Esta evolución ha ido en paralelo a las cifras y los casos de contagios y muertos que han ido aproximándose el entorno de las personas, o bien, la reiteración de la narrativa en los medios con las estadísticas como protagonistas. Se podría decir que es el capital acumulado del miedo y las consecuencias de los datos, así como, los diagnósticos médicos.

En una comparativa entre abril del 2020 y febrero de 2021, se observó un crecimiento de quienes afirmaron tener miedo al contagio y disminuyó el temor a la afectación económica, como miedo principal (Tabla 3).

Tabla 3

¿En estos momentos a qué le tiene más miedo?

\begin{tabular}{lcc}
\hline & $\begin{array}{c}\text { Abril 2020 } \\
\%\end{array}$ & $\begin{array}{c}\text { Febrero 2021 } \\
\%\end{array}$ \\
\hline A contagiarse de coronavirus & 34,5 & 38,8 \\
\hline A que su economía se vea afectada & 39,8 & 29,1 \\
\hline A ser víctima de algún delito & 19,9 & 24,8 \\
\hline
\end{tabular}

Fuente: Consulta Mitofsky (2021). 
Respecto del miedo a contagiarse, si bien este se ha ido atenuando con el transcurso de los meses, hubo un pico en mayo de $2020(40,5 \%)$ y luego en julio 2020 descendió $(38,7 \%)$, pero a partir de diciembre 2020 $(40,9 \%)$ este volvió a elevarse y no ha descendido significativamente, pues en febrero de 2021 el porcentaje llegó a 38,8\%. Por su parte, en el caso de la afectación económica, esta fue mayor en los primeros meses, por ejemplo, en abril 2020 llegó a 40,6\%; sin embargo, el resto del año se mantuvo, o bien, descendió (29,1\% en febrero 2021).

Tabla 4

¿Qué tanto miedo tiene de contagiarse usted o su familia, y a morir a causa del coronavirus?

\begin{tabular}{lcccc}
\hline & \multicolumn{2}{c}{ Miedo contagio } & \multicolumn{2}{c}{ Miedo a morir } \\
\hline & Febrero & Febrero & Febrero & Febrero \\
& 2020 & 2021 & 2020 & 2021 \\
& $\%$ & $\%$ & $\%$ & $\%$ \\
\hline Mucho/Algo & 43,9 & 80,5 & 32,2 & 73,3 \\
\hline Poco/Nada & 34,9 & 17,9 & 62,5 & 22,6 \\
\hline
\end{tabular}

Fuente: Consulta Mitofsky (2021).

En cuanto al temor al contagio puede decirse que este aumentó de manera progresiva y sostenida, con algunos picos que en la actualidad son muy significativos. En tanto que respecto del miedo a morir, este fue algo más reducido que en el indicador anterior.

Esta circunstancia se ha producido en paralelo a tener personas infectadas cerca de su entorno o en los lugares donde la gente se mueve. Por ejemplo, según Consulta Mitofsky (2021) en marzo de 2020 el $81,8 \%$ de las personas entrevistadas afirmó no creer que había personas contagiadas a su alrededor versus un 13,6\% que indicó una respuesta afirmativa. En febrero de 2021, o sea, casi un año después, el $74 \%$ afirmó creer que había infectados en su entorno y 22,1\% señaló que no era su caso. Algo similar acontece con los conocidos, ya que en abril de 2020 un 76,1\% dijo que no tenía ningún conocido contagiado versus un 20,3\% que señaló que sí. Sin embargo, luego estas cifras se invirtieron, para llegar a febrero de 2021 con un 90,3\% de personas que señalaron conocer personas contagiadas versus un 9,1\% que indicó que no conocían. Por último, en cuanto a los fallecimientos en abril de 2020 un $90 \%$ de los entrevistados manifestó no tener ningún muerto 
por coronavirus conocido, hasta llegar a febrero de 2021 con un $75,8 \%$ de personas que afirmó tener conocidos fallecidos y 22,9\% que declaró que no era su caso.

Esta explicación muestra el contexto de lo que la gente dice sentir en el país según las encuestas aplicadas en torno al tema, que dibuja un clima emocional claro y en aumento del miedo al contagio y a la muerte. Si bien el gobierno federal no ha abordado la pandemia de forma alarmista, ello sí ha ocurrido en diferentes niveles del mismo y en los medios, ya que por ejemplo aun cuando las medidas de contención ante la emergencia sanitaria no hayan sido obligatorias y universales, las personas las asumieron mayoritariamente de manera voluntaria y constante, incluso pidiendo mayor dureza, pese a las campañas que exigían lo contrario.

Tras la definición del concepto y proceso de resiliencia, y habiendo realizado una caracterización de los miedos ciudadanos en México, ahora se va a ahondar y significar la resiliencia a través de entrevistas a la población, lo cual se esboza por medio de sus relatos directos de acciones, emociones, opiniones, actitudes y relaciones, entre otras.

\section{El proceso de resiliencia de personas y colectivos sociales}

A continuación se transcriben fragmentos de varias expresiones y señalamientos referentes al tema. Como se dijo, en ocasiones un mismo testimonio en una oración reúne varios indicadores, así como las estrategias se superponen y entrecruzan, y las acciones se reiteran o suman. Básicamente se trata de ilustrar algunas categorías y subcategorías elaboradas y presentadas en la Tabla 1 , y relacionarlas con obras y autores/as, y a la inversa.

\section{Resolver problemas, actuar}

Una estrategia de afrontamiento resiliente es focalizarse en la solución de problemáticas o en su modificación para mejorar la situación existente, por medio de ciertas acciones concretas, las que incluyen sobrellevar las circunstancias hasta transformarlas, o por lo menos transformarse y estar bien en medio de la adversidad. Para ello se desarrollan diversas actividades para manejar la situación o afrontarla activamen- 
te. (Manrique y Vidal, 2006; Morán et al., 2010; Morán et al., 2019; OPS, 2020)

A continuación se desglosan algunas de las actividades de afrontamiento y se despliegan sus respectivos testimonios.

\begin{tabular}{ll}
\hline Actividad & Testimonios \\
\hline Trabajar & - "La carga de trabajo es mayor y consume casi todo mi día \\
& $\begin{array}{l}\text { eso me distrae" (hombre, } 25 \text { años, maestro, Xochimilco). } \\
\text { - "No hay novedad en mi vida, me mantengo ocupada". } \\
\text { (mujer, 23 años, estudiante, Coyoacán). }\end{array}$ \\
\hline
\end{tabular}

$\mathrm{Al}$ respecto, se puede mencionar el aporte de Lazarus y Folkman (1986), quienes señalan que una opción de actuación es trabajar como siempre, o incluso más, para afrontar activamente la situación.

\begin{tabular}{ll}
\hline Actividad & Testimonios \\
\hline $\begin{array}{l}\text { Divertirse, } \\
\text { distraerse }\end{array}$ & $\begin{array}{l}\text { "Distraerme con cosas que me gusta hacer y pensar que } \\
\text { esto es una prueba para la sociedad". (hombre, 23 años, } \\
\end{array}$ \\
\hline
\end{tabular}

Igual que la actividad "trabajar", focalizarse en lo que agrada hacer o en los hobbies es algo similar para mantener la entereza en medio de la incertidumbre real o imaginaria. (Manrique y Vidal, 2006)

\begin{tabular}{|c|c|}
\hline Actividad & Testimonios \\
\hline $\begin{array}{l}\text { Hobbies, } \\
\text { pasatiempos, } \\
\text { ocio, pintar, leer, } \\
\text { cine, música, } \\
\text { juegos }\end{array}$ & $\begin{array}{l}\text { - "Hacer cosas que me gusten mucho". (mujer, } 18 \text { años, } \\
\text { empleada, Xochimilco) } \\
\text { - "Realizar actividades que no me permitan pensar } \\
\text { frecuentemente en esas cosas". (mujer, } 22 \text { años, } \\
\text { estudiante, Milpa Alta) } \\
\text { - "Leer y encontrar nuevas actividades". (mujer, } 29 \text { años, } \\
\text { estudiante, Tlalpan) }\end{array}$ \\
\hline
\end{tabular}

Como se aprecia por las respuestas, en lugar de ver las noticias de la televisión o las conversaciones de contagios en la colonia, de muertos, hospitalizados y lo terrible de la situación - ante la que aparentemente no es posible hacer nada más que seguir las cifras y cuidarse-, se opta por focalizar la atención en otras cosas. No es evasión y tampoco indiferencia ante el dolor, ni siquiera sobrevivencia mental: se trata de no dejarse contaminar por el desequilibrio emocional, especialmente

$7 \quad$ A veces no se pueden cambiar las circunstancias, pero sí la actitud, lo que recuerda a Gandhi y su frase "Sé el camino de lo que quieres ver en el mundo", y estar bien y sentirlo y modelarlo es importante. 
en aquellos amplios sectores que no viven directamente la problemática. Al respecto, Lazarus y Folkman (1986) recomiendan realizar pasatiempos y actividades productivas y reconfortantes para equilibran las emociones.

\begin{tabular}{ll}
\hline Actividad & Testimonios \\
\hline Descansar & - "En lo personal sí me benefició bastante por el traslado \\
& que me hacía de casa a la facultad, que eran 2 horas \\
& aproximadamente y por el trabajo que ahora lo realizo \\
& desde home office". (mujer 22 años, administradora, \\
& Milpa Alta) \\
& "Esto me trajo tiempo para descanso". (mujer, 22 años, \\
& estudiante, Milpa Alta) \\
\hline
\end{tabular}

En este caso, se valora el tiempo de descanso que antes no se tenía y ahora se posee y aprecia más, lo cual coincide con actuar para relajarse y también con el espacio emocional (Manrique y Vidal, 2006).

\begin{tabular}{ll}
\hline Actividad & Testimonios \\
\hline Ejercicio & - "Salir a correr al campo, un lugar libre". (hombre, 22 años, \\
físico & auxiliar contable, Milpa Alta) \\
& - "Hacer actividades que me ayuden a relajarme, por \\
& ejemplo, hacer ejercicio". (mujer 22 años, estudiante, \\
& Tlalpan) \\
\hline
\end{tabular}

Si bien hay quien expresa su queja de no poder salir o hacer deporte como antes, también hubo expresiones como los ejemplos, en donde se afirma tener más tiempo para realizar actividades físicas. Al respecto, ejercicio y deporte son también actividades que componen la estrategia de manejo o afrontamiento activo. (Morán et al., 2010)

\begin{tabular}{ll}
\hline Actividad & Testimonios \\
\hline $\begin{array}{l}\text { Dieta } \\
\text { adecuada }\end{array}$ & $\begin{array}{c}\text { "Cuidar mis hábitos alimenticios". (hombre, 24 años, } \\
\text { asistente, Tlalpan) }\end{array}$ \\
\hline
\end{tabular}

El sedentarismo en el trabajo y estudio debido a la permanencia frente a la computadora u otras pantallas, continuamente conectados, junto con la ansiedad de las emociones sentidas, fomentan y facilitan la obesidad que parece aumentar y favorecer otras enfermedades. No obstante, las medidas de reclusión también posibilitaron una mayor consciencia por el cuidado de la sana nutrición, es decir, el desarrollo de actividades que muestran un actuar propositivo, toda vez que estas benefician holísticamente. 


\begin{tabular}{ll}
\hline Actividad & Testimonios \\
\hline Pendientes & - "Una oportunidad para realizar actividades, que no \\
o proyectos & harías por falta de tiempo". (mujer, 29 años, estudiante, \\
postergados & Tlalpan) \\
& $\begin{array}{l}\text { - "Desestresarme realizando alguna actividad, limpiar, } \\
\text { pintar, arreglar muebles". (mujer 22 años, estudiante, } \\
\text { Milpa Alta) }\end{array}$ \\
\hline
\end{tabular}

Las opiniones indican que hubo quienes optaron por hacer arreglos caseros pendientes o nuevos, como pintar paredes, mover muebles, hacer limpieza a fondo o de objetos, es decir, aprovechar el tiempo y mejorar las condiciones del espacio donde se habita, desde la recámara a toda la casa. En este caso, los proyectos postergados fueron abordados en el nuevo contexto para finalmente realizarlos y sobrellevar la situación.

\section{Equilibrar emociones, actuar}

Otra forma de resiliencia se relaciona con el mundo emocional y con gestionar, transitar y equilibrar las emociones, e involucra liberar el estrés, la expresión emocional, el despliegue de aceptación y adaptación, hasta el aprendizaje y el desarrollo de las capacidades cognitivas. En este sentido, se trata de un esfuerzo adaptativo que conlleva apoyo emocional y aceptación (Lazarus y Folkman, 1986; Morán et al., 2019). Cabe recordar al respecto el contexto de miedo a la enfermedad y a la afectación económica, en particular al contagio y muerte propia o de algún familiar que se mostró con anterioridad en las encuestas (Consulta Mitofsky, 2021).

\begin{tabular}{ll}
\hline Actividad & Testimonios \\
\hline Diversiones & $\begin{array}{l}\text { "Valorar mi vida, el disfrutar todo como si fuera el } \\
\text { último día que saldré". (mujer, 23 años, estudiante, } \\
\end{array}$ \\
& Coyoacán) \\
\hline
\end{tabular}

En este caso, las actividades como la diversión van más allá del deseo inmediato, sino que parte intrínseca del disfrute de la vida con conciencia, lo que la convierte en un estilo y estrategia de afrontamiento activo y satisfactorio, así como un esfuerzo y refuerzo de equilibrio emocional (Morán et al., 2010). 


\begin{tabular}{|c|c|}
\hline Actividad & Testimonios \\
\hline $\begin{array}{l}\text { Expresar } \\
\text { lo que se } \\
\text { siente, } \\
\text { desahogo }\end{array}$ & $\begin{array}{l}\text { - "Poder expresarme y para poder darle un valor a todo } \\
\text { aquello que me sucedió". (mujer } 19 \text { años, estudiante, Milpa } \\
\text { Alta) } \\
\text { - "Creo que de manera general el expresar mis emociones } \\
\text { me ha servido para liberarme, no cargar con un peso } \\
\text { e incluso ser agradecida". (mujer, } 19 \text { años, estudiante, } \\
\text { Gustavo Madero) }\end{array}$ \\
\hline
\end{tabular}

El poder expresar las emociones es básico para la salud, y si no se soluciona el problema, al menos este se comparte y alivia, se saca fuera evitando el enquistamiento que bloquea y congela emociones y provoca enfermedad. Así también, la gratitud de todo lo que se posee - no solo de lo material, también por lo que se es, y no siempre reconocido y valorado, menos agradecido-. En este punto de expresión y desahogo parece haber contradicción, incluso entre los mismos autores, pues hay quienes los consideran satisfactorio como afrontamiento resiliente (Morán et al., 2010), mientras que otros lo señalan como parte de la reiteración del malestar y resultado contraproducente y no resiliente (Morán et al., 2019).

\begin{tabular}{ll}
\hline Actividad & Testimonios \\
\hline $\begin{array}{l}\text { Manifestar } \\
\text { y demostrar }\end{array}$ & "Sentir apoyo de tu familia, amigos". (mujer, 23 años, \\
afecto & $\begin{array}{l}\text { administradora, Tlalpan) } \\
\text { "Mejorar la comunicación con mi familia". (hombre, 20 } \\
\text { años, trabajador, Xochimilco) }\end{array}$ \\
\hline
\end{tabular}

En general hubo muchas muestras de reencuentro familiar, así como, revalorización de amistad e intimidad ${ }^{8}$.

\begin{tabular}{ll}
\hline Actividad & Testimonios \\
\hline Conversar & "Al estar en cuarentena ayuda a tener más comunicación \\
& $\begin{array}{l}\text { con tu familia". (hombre, } 20 \text { años, trabajador, } \\
\text { Xochimilco) }\end{array}$ \\
\hline
\end{tabular}

En este caso, expresar lo que se siente y también compartir opiniones, sensaciones, vivencias, comunicar e intercambiar, afectos y pensamientos, es una forma de estar con los otros, acercarse y tocarlos en la distancia, con las ideas, las emociones y las palabras.

8 Esto se recoge en los puntos de la relación con los otros. 


\begin{tabular}{ll}
\hline Actividad & Testimonios \\
\hline $\begin{array}{l}\text { Relajación, } \\
\text { visualización, }\end{array}$ & - "Trato de llevar un método de relajación para \\
meditación & que no me domine". (hombre, 25 años, maestro, \\
& Xochimilco) \\
& "Distraerme o realizar actividades diferentes \\
& para relajarme". (hombre, 20 años, trabajador, \\
& Xochimilco) \\
& "Relajarme y pensar positivo". (mujer, 22 años, \\
& estudiante, Xochimilco) \\
\hline
\end{tabular}

Como se observa en los testimonios donde se expresa la importancia del pensamiento positivo- que hay quien nombra como optimismo inteligente (Avia y Vázquez, 2011)—, ante el estrés, la incertidumbre y el miedo ya visto en las encuestas, lo mejor es tranquilizarse y serenarse, relajarse.

\begin{tabular}{ll}
\hline Actividad & Testimonios \\
\hline Mundo & - "Una oportunidad de valorar nuestra libertad, ver a \\
espiritual, & nuestros seres queridos, amigos, familiares, pero sobre \\
religión, & todo aprender en todo momento, en cuestión académica, \\
oración & $\begin{array}{l}\text { personal, espiritual". (mujer, 23 años, estudiante, } \\
\text { Coyoacán) }\end{array}$ \\
\hline
\end{tabular}

Como se aprecia, los entrevistados ponen en valor las relaciones familiares, las actividades de la vida, incluso la parte espiritual, que se apunta como clave y recurso para el crecimiento de la conciencia (Martínez, 2013).

\begin{tabular}{ll}
\hline Actividad & Testimonios \\
\hline Aceptación & - "Aprender a valorar las cosas". (mujer, 22 años, \\
del cambio, & estudiante, Tlalpan) \\
realista y & - "El encierro no es fácil para nadie y lo de la gratitud \\
flexible & creo que ha sido a partir de valorar todo lo que tengo y \\
& los momentos que comparto con mi familia". (mujer, 23 \\
& años, estudiante, Coyoacán) \\
& "El darse cuenta que a pesar de esto se puede salir \\
& adelante". (hombre, 25 años, maestro, Xochimilco) \\
& "Aceptar todo lo que no me es posible cambiar". (mujer, \\
& 27 años, estudiante, Tlalpan)
\end{tabular}

El último testimonio es clave y recuerda la famosa oración de la serenidad Niebuhr: "Dios concédeme serenidad para aceptar las cosas que no puedo cambiar, valor para cambiar aquellas que puedo, y sabiduría para reconocer la diferencia". En este caso, las actividades de aceptación como esfuerzo adaptativo (Morán et al., 2010) y equili- 
brio emocional (Lazarus y Folkman, 1986) han resultado fundamentales.

\begin{tabular}{|c|c|}
\hline Actividad & Testimonios \\
\hline $\begin{array}{l}\text { Capacidad } \\
\text { continua de } \\
\text { aprendizaje, } \\
\text { competencias } \\
\text { cognitivas }\end{array}$ & $\begin{array}{l}\text { - "Sí, es una oportunidad, llegar a poder explotar } \\
\text { herramientas que jamás habías utilizado y tener un } \\
\text { poco de tiempo para ti". (mujer, } 23 \text { años, estudiante, } \\
\text { Tlalpan) } \\
\text { - "Al principio me quedé sin trabajo al igual que mi } \\
\text { esposo y uno de mis hijos; los cambios laborales } \\
\text { me hicieron aprender y adaptarme a un sistema de } \\
\text { trabajo el cual no me gusta, pero no descarto pues } \\
\text { he aprendido mucho". (mujer, } 54 \text { años, maestra, } \\
\text { Tláhuac) }\end{array}$ \\
\hline
\end{tabular}

De la aceptación deriva la adaptación —la que a veces o bien siempre-, pasa por el aprender a aprender, renovarse o morir, estar receptivos a lo nuevo, fluir con el cambio (Csikszentmihalyi, 2008), en una palabra: actualizarse, en este caso, entendida como parte de la flexibilidad, y del aprovechamiento de las oportunidades que ofrece la crisis (Vera et al., 2006).

\begin{tabular}{ll}
\hline Actividad & Testimonios \\
\hline $\begin{array}{l}\text { Capacidad de } \\
\text { adaptación, }\end{array}$ & - "De ser más conscientes. De ver las cosas de \\
creatividad, & otra forma". (mujer, 43 años, servicio doméstico, \\
decisión, & Xochimilco) \\
iniciativa, & "Las ganas de salir adelante". (hombre, 50 años, \\
interacción, & empleado, Xochimilco) \\
perseverancia & $\begin{array}{l}\text { "Darte cuenta de que la vida es muy corta y } \\
\text { tenos que aprovecharla". (mujer 43 años, servicio }\end{array}$ \\
\hline
\end{tabular}

Los testimonios muestran que adaptarse a la vida, salir adelante, aprovecharla, y el poder de cambiar no solo el hacer, sino también la mirada concuerdan con la comprensión ante la situación y tal vez una reinterpretación positiva de la misma (Morán et al., 2010). 


\begin{tabular}{|c|c|}
\hline Actividad & Testimonios \\
\hline $\begin{array}{l}\text { Autoconocimiento, } \\
\text { autoestima, } \\
\text { autoconfianza }\end{array}$ & $\begin{array}{l}\text { - "En el sentido de crecer personalmente". (mujer, } 23 \\
\text { años, estudiante, Coyoacán) } \\
\text { - "Pues nos ha dejado reencontrarnos y valorar en } \\
\text { verdad lo que tenemos y que en algún momento } \\
\text { descuidamos, dándole más peso a lo material, } \\
\text { aunque en ocasiones nos ayude a estar bien". } \\
\text { (mujer, } 54 \text { años, maestra, Tláhuac) } \\
\text { - “Tener más tiempo para mí que me sirvió para } \\
\text { conocerme mejor". (mujer, } 21 \text { años, estudiante, } \\
\text { Gustavo Madero) } \\
\text { - "Aprender a soltar personas que no me hacen bien, } \\
\text { aprender a quererme a mí misma, mejorar mi } \\
\text { autoestima, casi terminar mi licenciatura". (mujer, } \\
23 \text { años, estudiante, Coyoacán) }\end{array}$ \\
\hline
\end{tabular}

En este caso, los testimonios apuntan a que el autoconocimiento y la autoestima parecen haberse cultivado en tiempos de encierro y pandemia, esto es, contar con más tiempo para estar consigo mismo que al parecer se empleó para el autoconocimiento (Manrique y Vidal, 2006; Morán et al., 2010).

\begin{tabular}{ll}
\hline Actividad & Testimonios \\
\hline $\begin{array}{l}\text { Equilibrio } \\
\text { emocional }\end{array}$ & - "No decaer y tener la esperanza de que poco a poco irá \\
o gestión & mejorando todo esto". (hombre, 20 años, trabajador, \\
emocional & Xochimilco) \\
& "Cuidarme, no caer en depresión o en desesperación". \\
& (mujer, 22 años, administrativa, Milpa Alta) \\
& "La esperanza y el amor. En general, sentir eso me afecta \\
& en vida, porque me hace luchar y no rendirme a la \\
& primera de cuentas, esperar lo mejor de cada situación \\
& y tratar de pensar que todo sucede por algo y que por \\
& alguna razón no pasó de otra forma". (mujer, 21 años, \\
& estudiante, Gustavo Madero) \\
\hline
\end{tabular}

Respecto de esta actividad, los testimonios muestran un intento de equilibrar los aspectos emocionales dolorosos, entre el consuelo y la consciencia, ligados a la aceptación y valoración de lo positivo (Vera et al., 2006) que también hubo en este difícil periodo, lo cual coincide nuevamente con un esfuerzo adaptativo y reinterpretación positiva (Morán et al., 2010), donde aparece la esperanza y el amor (Avia y Vázquez, 2011; Seligman, 2014). 


\begin{tabular}{ll}
\hline Actividad & Testimonios \\
\hline Actitud & - "Valorar lo que vivimos día con día". (hombre, 28 años, \\
positiva, & empleado de gobierno, Milpa Alta) \\
optimismo, & - "Mantener la esperanza de que todo saldrá bien". \\
asertividad & (hombre, 50 años, empleado, Xochimilco) \\
& $\begin{array}{l}\text { "Trato de ser positiva y ver el lado bueno". (mujer, } 18 \\
\text { años, empleada, Xochimilco) }\end{array}$ \\
\hline
\end{tabular}

Los testimonios dan cuenta aquí de una actitud positiva ante la vida, así como esperanza, autoanálisis emocional y la comprensión de algo más grande que el propio ser. (Avia y Vázquez, 2011)

\begin{tabular}{ll}
\hline Actividad & Testimonios \\
\hline $\begin{array}{l}\text { Responsabilidad, } \\
\text { autonomía, } \\
\text { independencia }\end{array}$ & $\begin{array}{l}\text { "Ser más conscientes de la salud". (mujer, } 47 \text { años, } \\
\text { empleada, Xochimilco) }\end{array}$ \\
& "Ser más cuidadosos en las medidas sanitarias y \\
& Xochimilco) \\
- & "Para tomarer, 33 años, servicio doméstico, \\
& (mujer, 47 años, empleada, Xochimilco) \\
- "Para poder pensar en lo que la humanidad le está & \\
& ocasionando al planeta". (hombre, 22 años, auxiliar \\
& contable, Milpa Alta) \\
- "Darnos cuenta que tenemos que cuidar el planeta \\
donde vivimos". (mujer, 43 años, servicio doméstico, \\
Xochimilco)
\end{tabular}

La reiteración del cuidado de la salud y la higiene tuvo lugar en diferentes momentos de las entrevistas, del mismo modo que el cuidado del planeta, que también apareció en varias ocasiones: autocuidado y el cuidado del otro y del mundo. 


\begin{tabular}{ll}
\hline Actividad & Testimonios \\
\hline Empatía, & - "Pues la pandemia nos hace replantearnos la forma en \\
comprensión, & que nos relacionamos con otros seres vivos (humanos y \\
simpatía & no humanos)". (hombre, 24 años, asistente, Tláhuac) \\
& "Amor, porque me he permitido compartir muchísimo \\
& más tiempo de calidad con las personas que más amo, \\
& pero también tristeza por todas las personas que han \\
& perdido la batalla durante esta epidemia y por todos \\
& aquellos que se han quedado sin empleo y sufren crisis \\
& económicas fatales. Agradecimiento porque todas \\
& las personas que amo están sanas". (mujer, 22 años, \\
& administradora, Milpa Alta) \\
- "Darnos cuenta de que estamos hechos nuevamente, y & sobre todo, el saber qué hacer en momentos difíciles, y \\
& aunque está por demás, el decir la unión en todo lo que \\
& conlleva". (mujer, 54 años, maestra Tláhuac) \\
\hline
\end{tabular}

Aunque más adelante se abordará el tema de la autorreflexión y la reflexión acerca de las relaciones con el entorno y las otras personas, aquí se deja constancia de la empatía y la comprensión en las relaciones (Manrique y Vidal, 2006; Morán et al., 2010).

\begin{tabular}{ll}
\hline Actividad & Testimonios \\
\hline Tolerancia a la & - "Es una gran oportunidad para darnos cuenta de que \\
incertidumbre & no todo está dado por hecho, la vida puede cambiar \\
paciencia, & en un minuto para cualquier persona". (hombre, 25 \\
flexibilidad & años, profesor, Xochimilco) \\
& "Poco a poco fui tratando de tomar de la mejor \\
& manera todo lo que está pasando". (mujer, 22 años, \\
& estudiante, Milpa Alta) \\
& "Al comienzo de la pandemia sentía que nada tenía \\
& sentido; de cierta manera me sentía frustrada al \\
& no poder salir y sentir el miedo de contagiarme \\
& en el transporte público, porque al principio lo \\
& que sembraron fue terror más no medidas de \\
& protección, y pues en ningún lugar me sentía segura, \\
& al paso del tiempo fui tomando las cosas con más \\
& tranquilidad y de la mejor manera, poco después \\
& me sentí muy afortunada y en estos momentos \\
& doy gracias, porque ningún miembro de mi familia \\
& ha contraído el virus y aunque la economía de mi \\
& familia no es muy grande, hemos sabido sobrellevar \\
& la situación y de igual manera damos gracias de que \\
& no nos hemos quedado sin trabajo". (mujer, 22 años, \\
& administradora, Milpa Alta) \\
\hline
\end{tabular}


En este caso, y como diversas corrientes psicológicas propugnan, tanto la tolerancia a la frustración como la paciencia y la flexibilidad se pusieron en práctica frente al miedo (Manrique y Vidal, 2006).

\begin{tabular}{ll}
\hline Actividad & Testimonios \\
\hline Crisis como & - "Puede ser que sí, creo que puede ser una oportunidad \\
partunidad & debemos sacar lo bueno a cualquier situación". (mujer, \\
& 21 años, estudiante, Gustavo Madero) \\
& - "Una oportunidad para retomar cosas que teníamos \\
& pendientes; al hacer todo en línea nos ahorramos \\
& tiempo de transporte, de esta manera podemos leer \\
& el libro que teníamos pendiente o pasar tiempo con la \\
& familia". (hombre, 22 años, estudiante, Milpa Alta) \\
& "Sí, muchas personas han cambiado conductas \\
& respecto de lo que sucede, siendo por ejemplo que \\
& son más empáticos acerca de lo que ocurre y con las \\
& personas, pero por otro lado, muchas personas han \\
& visto y aprovechan esta situación para su propio bien; \\
& siendo así que hay diversos puntos y perspectivas de \\
& oportunidad". (mujer, 19 años, estudiante, Gustavo \\
& Madero) \\
\hline
\end{tabular}

Lo que aquí se aprecia es una propuesta del nuevo enfoque resiliente: la oportunidad (Vera et al., 2006), esto es, oportunidad que pasa por cuestiones prácticas - incluso por aprovecharse interesadamente del prójimo-, que también abre las puertas a un cambio de vida para mejor. Se aprecia nuevamente el esfuerzo de reinterpretación positiva y de aceptación y adaptación (Morán et al., 2010; 2019).

\begin{tabular}{ll}
\hline Actividad & Testimonios \\
\hline Sentido y & • "Valor por la vida, familia, amigos y conocidos". (mujer, \\
propósito & 19 años, comerciante, Milpa Alta) \\
de vida, & " "Todas las expectativas de vida y superación que se \\
motivación & tienen". (mujer, 54 años, maestra, Tláhuac) \\
& - "Darle sentido a lo que está pasando". (mujer 21 años, \\
& estudiante, Gustavo Madero) \\
& "El tiempo de calidad que, tenido con mi mamá y mi \\
& perro, el poder conocerme a más a mí misma y definir \\
& qué es lo que quiero para un futuro". (mujer, 23 años, \\
& estudiante, Coyoacán) \\
\hline
\end{tabular}

En esta actividad y sus testimonios se puntualiza el valor de la familia, y el sentido de vida, el que va desde la logoterapia (Frankl, 2003) hasta la psicología positiva (Seligman, 2014), pasando por los clásicos de la filosofía: propósito y motivación en tiempos resilientes. De he- 
cho, puede significar una reinterpretación de la existencia con conciencia en algunos casos (Martínez, 2013), aunque cabe señalar eso sí que en las expresiones recabadas en este punto y todos los demás, no se observa un cuestionamiento a la narrativa oficial en modo alguno, sino que más bien reitera sus discursos y adaptación a los miedos y medidas que de derivan él.

Finalmente, si bien no hubo ninguna expresión de humor entre las y los entrevistados, se desea mostrar algunas ilustraciones respecto del tema.

Figura 1

Resiliencia

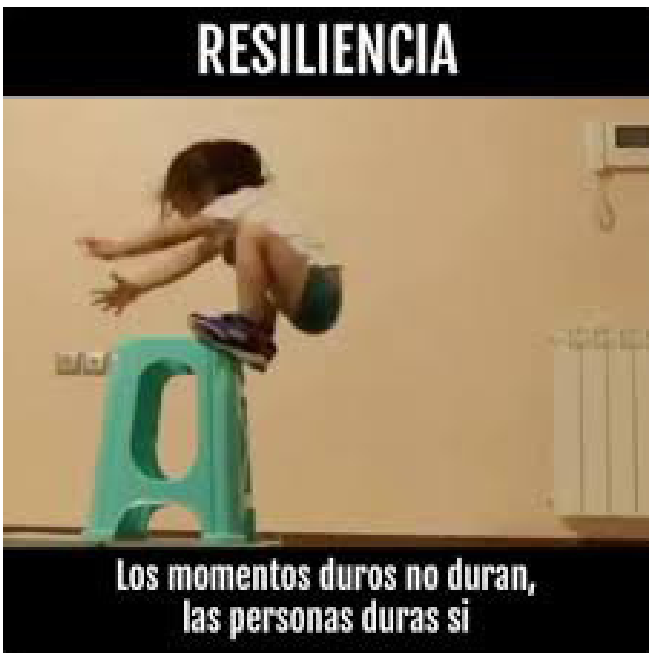

Fuente: Emprendedor eficaz (2020).

Los chistes, las caricaturas y los memes irrumpieron y se viralizaron para dar un toque de humor a la situación, aliviando tensión y proporcionando aire fresco (Jaúregui y Fernández, 2012). Así, en la Figura 1 se observa un meme con la palabra "resiliencia", mientras que el mensaje escrito apunta a que todo pasa y las personas fuertes, permanecen (Avia y Vázquez, 2011), al tiempo que la imagen muestra a un niño que parece a punto de caer. Al respecto, hay que subrayar que en tiempos de crisis el humor o los medios humorísticos, presentan acercamientos solidarios o mensajes reflexivos en cuanto a la realidad, con lo cual persiguen una sonrisa más que una risa. 
Figura 2

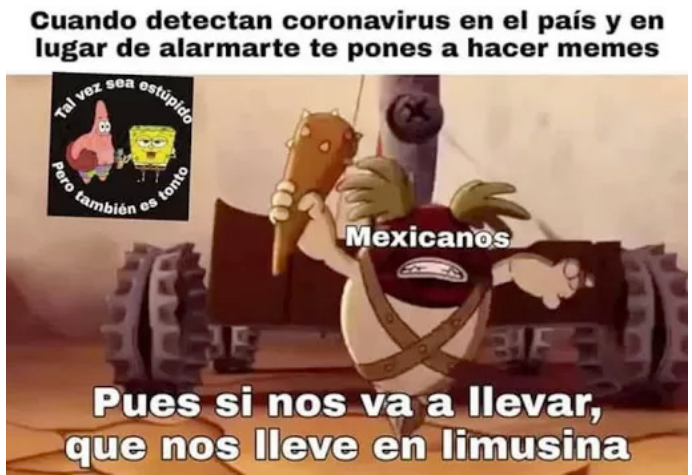

Fuente: Masdemx (2020).

La Figura 2, en tanto, es una imagen respecto de la disposición, inmediatez y eficacia de la creación de memes, que representan una forma de afrontamiento por medio de la acción, así como una manera de equilibrar emociones gracias a su mensaje, toda vez que la comunicación relaciona y une, esto es, acoge los tres estilos de afrontamiento resiliente que se han abordado hasta aquí, aunque es posible clasificarlo en el ámbito emotivo, fundamentalmente.

\section{Relación con los otros}

Las relaciones sociales satisfactorias son fundamentales. En efecto, el círculo de la familia cercana y extensa, así como la red de amistades, acompaña y apoya a las personas en su tránsito de gestión emocional, como la reducción y alivio de tensión, y el sentirse rodeada y contenida de la comprensión y calor humanos. Si bien las relaciones familiares aparecen reiteradamente en el punto del manejo emocional, tiene su rol principal en la relación con los otros (Manrique y Vidal, 2006).

\begin{tabular}{ll}
\hline Actividad & Testimonios \\
\hline Sociabilidad & • "Poder aprovechar bien el tiempo con las personas que \\
& queremos, agradecer el trabajo que tenemos, y la salud". \\
& (mujer, 22 años, estudiante, Milpa Alta) \\
& "Interactuar con mi entorno de manera general, \\
& compartiendo ideas y liberando energía de una u otra \\
& forma". (hombre, 22 años, estudiante, Milpa Alta) \\
& " "El aprender a valorar los momentos más insignificantes \\
& de convivencia". (mujer, 22 años, estudiante, Gustavo \\
& Madero) \\
&
\end{tabular}


En los relatos la convivencia, así como interactuar, compartir y ser con los otros se reconoce como una actividad fundamental, paradojalmente con aún mayor intensidad en tiempos en donde se predica el distanciamiento social y el quedarse en casa.

Por su parte, ante la situación de estrés y temor que se ha descrito, y como parte del manejo emocional y relacional, se puede mencionar la ayuda especializada en problemas mentales y emocionales.

\begin{tabular}{|c|c|}
\hline Actividad & Testimonios \\
\hline $\begin{array}{l}\text { Ayuda } \\
\text { profesional, } \\
\text { ayuda } \\
\text { emocional y } \\
\text { consejo }\end{array}$ & $\begin{array}{l}\text { - "Creo que algo que he aprendido de mi carrera es que } \\
\text { la salud mental es un tema importante y que asistir a } \\
\text { terapia no solo es para aquellos que tengan un problema } \\
\text { mental, por lo que creo que ir a terapia es una forma en la } \\
\text { que se puede hablar de las emociones negativas; sé que } \\
\text { hay ocasiones en las que no se puede asistir a terapia por } \\
\text { lo que incluso realizar una actividad que me guste y me } \\
\text { distraiga podría ser una manera de despejar la mente". } \\
\text { (mujer, } 19 \text { años, estudiante, Gustavo Madero) }\end{array}$ \\
\hline
\end{tabular}

Como se lee en este testimonio, cuando sea necesario y se pueda, la ayuda profesional en salud mental, también como interacción saludable puede ser muy positiva.

\begin{tabular}{ll}
\hline Actividad & Testimonios \\
\hline $\begin{array}{l}\text { Ayuda de } \\
\text { familia, }\end{array}$ & - "Podemos convivir con la familia". (mujer, 19 años, \\
amistades, & comerciante, Milpa Alta) \\
expresar, & Milón de la familia". (hombre, 28 años, empleado gobierno, \\
escuchar, & - "Solo para ver a nuestros familiares más tiempo". (mujer, 22 \\
compartir & años, estudiante, Milpa Alta) \\
& - "El disfrutar a mi familia". (hombre, 50 años, empleado, \\
& Xochimilco) \\
& - "Que mi familia se recuperó". (mujer, 18 años, empleada) \\
& - "Convivir más con mi familia conocerla y más y apreciarla". \\
& (mujer, 19 años, comerciante, Milpa Alta) \\
\hline
\end{tabular}

La unión, convivencia y ayuda familiar resultaron relevantes e importantes, por no decir básicas y fundamentales para la resiliencia ${ }^{9}$.

9 Si bien en los medios se reiteró la problemática de violencia hacia las mujeres en el hogar durante la cuarentena, lo cierto es que en esta investigación no apareció, incluso tampoco lo hizo en otros estudios llevados a cabo en esos momentos en el país, lo cual no significa que no existiera. Lo que sí apareció una y otra vez es la satisfactoria comunicación y convivencia familiar, y el aporte clave que esta institución tuvo para la sobrevivencia material y la gestión emocional de sus miembros. 


\begin{tabular}{ll}
\hline Actividad & Testimonios \\
\hline Grupos de & • "En el sentido personal de aprender a conocernos a \\
apoyo social, & nosotros mismos, convivir con la familia de otro modo y \\
pertenencia & humanitario en apoyar a las personas que lo necesitan". \\
& (mujer, 22 años, estudiante Tlalpan) \\
& " "Es la oportunidad para ser más conscientes el uno con \\
& el otro". (hombre, 50 años, empleado, Xochimilco) \\
& "Voy a ser muy contradictoria, pero el saber que \\
& podemos apoyarnos entre 'todos' y que el permanecer \\
& encerrados y tomar las medidas, lo agradecemos entre \\
& todos los que nos estamos cuidando". (mujer, 23 años, \\
& estudiante, Coyoacán) \\
\hline
\end{tabular}

En momentos de miedo como el vivido, el apoyo de todo tipo, desde la comunicación hasta lo afectivo, pasando por la ayuda material, y la insistencia en el cuidado de la salud individual y colectiva se transforma en el bien más preciado.

\begin{tabular}{|c|c|}
\hline Actividad & Testimonios \\
\hline $\begin{array}{l}\text { Pertenencia, } \\
\text { cohesión social }\end{array}$ & $\begin{array}{l}\text { - "Lo que está ocurriendo puede ser una oportunidad } \\
\text { para agradecer el tiempo, relaciones y recursos que } \\
\text { se tienen, por ejemplo, es una oportunidad para que } \\
\text { las familias puedan fortalecer los lazos existentes } \\
\text { o crearlos". (mujer, } 19 \text { años, estudiante, Gustavo } \\
\text { Madero) }\end{array}$ \\
\hline
\end{tabular}

La identidad y pertenencia al círculo de relaciones y especialmente al seno familiar o la red de parentesco ha quedado más que clara en estos tiempos a través de los testimonios recabados.

\begin{tabular}{|c|c|}
\hline Actividad & Testimonios \\
\hline $\begin{array}{l}\text { Activismo, } \\
\text { reflexión social }\end{array}$ & $\begin{array}{l}\text { - “Ser más prudente en el consumo". (hombre, } 22 \text { años, } \\
\text { auxiliar contable, Milpa Alta) } \\
\text { - "Reconocer que las personas somos vulnerables y, por } \\
\text { lo tanto, tenemos que ser más conscientes de nuestros } \\
\text { hábitos de consumo, porque todo es parte de un mismo } \\
\text { problema (...) Siendo más consciente de mi consumo } \\
\text { y de la importancia que tiene tener salud". (mujer, } 27 \\
\text { años, estudiante, Tlalpan) } \\
\text { - "Pensar la situación en la que vivíamos". (hombre, } 22 \\
\text { años, auxiliar contable, Milpa Alta) }\end{array}$ \\
\hline
\end{tabular}

Ahora bien, más allá del apoyo práctico, emergen en los testimonios recabados la reflexión colectiva ante la situación, especialmente respecto del mundo material y consumista en el que se vive y la necesidad de cambiar los hábitos. 


\begin{tabular}{ll}
\hline Actividad & Testimonios \\
\hline $\begin{array}{l}\text { Ayudando a } \\
\text { otras personas } \\
\text { vulnerables }\end{array}$ & - "Podría ser un cambio en la ayuda comunitaria". \\
& (hombre, 22 años, estudiante, Milpa Alta) \\
& salido a apoyar a los demás, me muestran que juntos se \\
& puede generar un cambio". (mujer, 19 años, estudiante, \\
& Gustavo Madero) \\
- "No lo sé, pero tal vez el saber que comienzan las & buenas acciones por parte de todos haga el cambio". \\
& (mujer, 54 años, maestra, Tláhuac) \\
\hline
\end{tabular}

Tal como señalan Manrique y Vidal (2006) y la OPS (2020), la ayuda al prójimo forma parte de la relación con los otros y de la resiliencia colectiva de los pueblos.

\begin{tabular}{ll}
\hline Actividad & Testimonios \\
\hline Mejora & - "Más higiene, más educación y mejores servicios". \\
(mujer, 29 años, estudiante, Tlalpan) & "Sí, para reconfigurar los sistemas de salud, conocer \\
& los puntos débiles y ofrecer mejores condiciones a las \\
& personas más vulnerables". (mujer, 27 años, estudiante, \\
& Tláhuac) \\
- "Reconocer las deficiencias en el sistema de salud & y querer cambiarlo". (mujer, 27 años, estudiante, \\
& Tlalpan) \\
- "Muestras de valentía por parte de nuestros médicos/ & as". (mujer, 23 años, estudiante, Coyoacán) \\
\hline
\end{tabular}

Respecto de este punto, fueron varios los relatos que implicaron a las instituciones sanitarias y actores médicos como parte de un necesario y posible cambio para mejorar la sanidad y hasta el planeta mismo. De igual modo, se reiteró el tema del cuidado continuo de la salud, lo cual fue reiterado en los discursos políticos y mediáticos.

Todo lo anterior proporciona, en conjunto, un sentido de vida y una vida significativa (Csikszentmihalyi, 2008; Frankl, 2003; Seligman, 2011).

\section{Afrontamiento no productivo o la no resiliencia}

Finalmente, en los testimonios también pudo apreciarse que había personas que decidieron la estrategia de afrontamiento no productivo, esto es, evitar o desconocer, negar y hasta aplazar el problema, lo cual se relaciona con la negación y disociación (Levine y Frederick, 1996). 
Lo anterior se refiere a cómo enfrentar la situación real creada, resistirla, sobrellevarla o adaptarse a las circunstancias que esta comporta. En este caso, no hay resiliencia. No hubo nada parecido a esperar un milagro y tampoco se escucharon discursos sobre autoinculparse $^{10}$. No obstante, la no expresión de estas actuaciones no aplica aquí, pues el estudio solo recogió información de quienes accedieron a ofrecer su testimonio en las entrevistas, y no la de aquellos que se negaron o, al menos, no hubo personas entrevistadas que dijeran o insinuaran que no expresaban su opinión o su sentir de lo que estaban viviendo.

Finalmente, sobre ignorar, negar o evadir, hay que decir que sí hubo algunas expresiones entre los entrevistados, la mayoría encaminadas a afirmar que todo es negativo y nada se puede rescatar de lo que acontece.

\begin{tabular}{|c|c|}
\hline Actividad & Testimonios \\
\hline $\begin{array}{l}\text { Ignorar, negar, } \\
\text { evadir }\end{array}$ & $\begin{array}{l}\text { - "Se han perdido muchas cosas, salud, trabajo, muchas } \\
\text { otras cosas". (hombre, } 23 \text { años, estudiante, Milpa Alta) } \\
\text { - "En lo económico es grave, igual en lo laboral". } \\
\text { (hombre, } 28 \text { años, empleado de gobierno, Milpa Alta) } \\
\text { - "No puedo salir como antes". (mujer, } 18 \text { años, } \\
\text { empleada, Xochimilco) } \\
\text { - "La tecnología nos está absorbiendo demasiado y no } \\
\text { ponemos atención a los que nos rodean". (mujer, } 19 \\
\text { años, comerciante Milpa Alta) } \\
\text { - "No, nada es bueno, en ningún sentido". (mujer, } 22 \\
\text { años, administradora, Xochimilco) } \\
\text { - "No puedes convivir con todas las personas". (mujer, } 25 \\
\text { años, auxiliar administrativo, Milpa Alta) } \\
\text {-Todo para peor. Ya no vivimos como antes". (mujer, } 22 \\
\text { "Nada, no sirve de nada". (hombre, } 25 \text { años, maestro, } \\
\text { Xochimilco) }\end{array}$ \\
\hline
\end{tabular}

En estos casos, más bien se parte de la queja, la ira, la victimización, en lugar de ignorar o negar la realidad. Varios entrevistados opinaron que todo era malo y nada bueno, aunque numéricamente fueron muy pocos. La mayoría de ellos estaba en actitudes resilientes como las recogidas en la investigación y expuestas a lo largo del análisis.

10 Sin embargo, sí aparece en varias ocasiones el daño de la humanidad al planeta y cómo todo el mundo es responsable. 
En todo caso, más que evadir, lo resiliente en estos casos sería intentar no pensar en la pandemia, prevenir para no obsesionarse y, en la medida de lo posible, seguir con la vida. Tampoco — por lo menos en este estudio-hubo narraciones de consumo de sustancias (medicamentos, alcohol, cigarrillos o drogas) que conducen supuestamente a la evasión.

\begin{tabular}{ll}
\hline Actividad & Testimonios \\
\hline $\begin{array}{l}\text { Ignorar, negar, } \\
\text { evadir }\end{array}$ & $\begin{array}{l}\text { "Trato de no pensar en que está la pandemia, pero } \\
\text { aún así tomo mis precauciones". (hombre, 30 años, } \\
\text { empleado bancario Álvaro Obregón) }\end{array}$ \\
\hline
\end{tabular}

\section{Discusión y conclusiones}

Las personas podemos escoger aquello que investigamos, aquello que estudiamos. Y no podemos obviar que aquello que focalizamos, crece. $\mathrm{Si}$ andamos por la vida buscando o estudiando problema o deficiencias, lo vamos a hallar y en demasía. Contrariamente, si vamos buscando fortalezas o potencialidades, aquello que funciona, también lo vamos a encontrar (Grané y Forés, 2012, p. 9).

Tras la revisión de expresiones diversas y testimonios de múltiples experiencias, se reafirma la idea de la capacidad de resiliencia de individuos y grupos humanos, construida hacia el interior de cada quien y en interacción con el entorno y con los otros. No se trata de una técnica, sino de un cambio de enfoque de la realidad. Y es que la base de la resiliencia se afianza en el sentido de la vida y en la interacción con el prójimo (Vanistendael, 2010).

Reconocer que, en general, en México no se impusieron estrictas medidas obligatorias como ocurrió en otras latitudes, así también se debe indicar que buena parte de la población estuvo de acuerdo con ellas y las cumplió, incluso las propuestas voluntarias que tuvieron un amplio eco y aceptación popular.

Así mismo, si bien los discursos no tuvieron el tono de otros países - como en Francia, donde las voces expresaban que el país estaba en guerra, o bien, presentando al ejército como protagonista, como sucedió en España-, sí hubo pánico como resultado de la cobertura de los medios y la difusión de las diferentes administraciones, advirtiendo y recomendando, cuando no directamente amenazando. Entonces, si 
los temores empujan a sobrevivir, la resiliencia lo hace para adaptarse a las circunstancias puntuales o duraderas que tienen lugar en el plano de cada ser humano o de un colectivo social.

Repasando lo visto es posible afirmar que hay un sentimiento de miedo imperante como clima social del mundo. No obstante, como se ha visto en las encuestas presentadas (Consulta Mitofsky, 2020), en medio de este temor o paralelamente, en México también hubo lugar para un proceso de resiliencia, el cual como habilidad de construirse (Grané y Forés, 2012) y de resistir y aprender a vivir (Cyrulnik, 2007) ocurrió en 2020 en las experiencias de varias personas, sectores de la población y de la sociedad en su conjunto. Una resiliencia que subraya su carácter dinámico y regenerativo, como se denomina en la actualidad, que experimenta la adversidad como oportunidad de crecimiento (Vera et al., 2006).

Así, a lo largo de este texto, inspirado en algunos enfoques teóricos, pero sobre todo construido a partir de los testimonios de experiencias compartidas, se ha entretejido estilos y estrategias resilientes con actividades particulares, diversas y concretas, destinadas a practicar la resiliencia en tiempos difíciles como los actuales: pandemia, confinamiento, crisis económica e impactos psicológicos.

Poco a poco, y a partir de indicadores provenientes de la inspiración teórica (Lazarus y Folkman, 1986; Manrique y Vidal, 2006; Morán et al., 2010; Morán et al., 2019; OPS, 2020), así como de la práctica metodológica (Glaser y Strauss, 1967; Strauss y Corbin, 2002), se ha configurado una caracterización de la riqueza y diversidad resiliente de acciones sociales, psicológicas, personales, colectivas, emocionales y relacionales, varias de ellas compartidas y entretejidas.

En un planeta impactado psicológicamente (Sandín et al., 2020) y en un país envuelto en el miedo (Consulta Mitofsky, 2021), se desarrolló un sinnúmero de actividades tenientes a la sobrevivencia, adaptación y desarrollo, las que se focalizaron en lo favorable, positivo $\mathrm{u}$ optimista (Avia y Vázquez, 2011) con objeto de mantener la entereza y salirse del discurso y clima de terror importante, desconectándose de la narrativa y emoción dominante externa, y reconectándose con uno mismo y con los afectos más cercanos, con objeto de mantener la salud mental, ya que es en situaciones extremas cuando el sujeto tiene 
la oportunidad de reconstruir su forma de ver y entender el mundo y el sistema de valores de la existencia (Vera et al., 2006).

En este proceso resiliente y con la visión hacia dentro de cada cual también parece haber sido imprescindible la mirada del entorno y de los otros, incluso del planeta. Así las cosas, es posible concluir que de lo aparentemente desfavorable y doloroso, se obtuvieron resultados que favorecen la gratitud, la reflexión, la aceptación, la autorreflexión, el aprendizaje, la consciencia, la expresión, la comunicación y el acercamiento al otro/a.

Como se señaló, las crisis son oportunidades de despertar, de crecimiento de conciencia y el riesgo es no ser capaces de cambiar y construir en medio del dolor. Sin embargo, si esto se consigue hay maduración psicológica, desprendimiento del ego y encuentro con el ser (Martínez, 2013), oportunidades de resolver, aprender y regresar renovados a la vida con sentido (O'Hanton, 2005).

Mucho más se puede pensar, estudiar y decir en cuanto a los procesos de resiliencia prácticamente vividos por todo el mundo, con más o menos fortuna cada cual o capacidad de afrontamiento constructiva frente a las adversidades. Aquí se presentó una investigación testimonial del tema que, más allá de datos y relatos, invita a seguir ampliando y ahondando su estudio, pero sobre todo, convida a la más auténtica y comprometida reflexión, para conservar lo positivo y ahora revalorizado del viejo mundo que, como constelaciones en el cielo, nos orientaron en nuestro navegar en el infierno, toda vez que vayamos diseñando el nuevo mundo hacia el que nos dirigimos con los mejores valores pasados y las mejores expectativas futuras.

\section{Referencias}

Avia, M. D. y Vázquez, C. (2011). Optimismo inteligente. Alianza Editorial.

Bloomberg /Chang, R., Hong, J., y Varley, K. (24 de noviembre de 2020). México, el peor país para vivir durante la pandemia de COVID-19, según ranking de Bloomberg. El Financiero. https:// www.elfinanciero.com.mx/salud/mexico-el-peor-pais-para-vivir-durante-pandemia-de-covid-19-segun-ranking-debloomberg/ 
Bruner, J. (2002). La fábrica de historias. Fondo de Cultura Económica.

Consulta Mitofsky (2021). El coronavirus en México. Consulta.mx. http://www.consulta.mx/index.php/encuestas-e-investigaciones/item/1425-covid-nal

Costa, C. (2011). Tratamiento informativo de la crisis de salud pública: Los titulares sobre gripe A en la prensa española. Revista de la SEECI, 14(25), 43-62. https://doi.org/10.15198/seeci.2011.25.29-42

Creswell, J. (2005). Educational research: Planning, conducting ans evaluating quantitative and qualitative research. Pearson.

Cyrulnik, B. (2007). La maravilla del dolor. El sentido de la resiliencia. Granica.

Cyrulnik, B. (2010). Neurología y resiliencia. En M. Manciaux (Comp.), La resiliencia: resistir y rehacerse (pp. 175-184). Gedisa.

Csikszentmihalyi, M. (2008). Fluir. Kairós.

Denzin, N. y Lincoln, Y. S. (2012). Manual de investigación cualitativa. Gedisa.

Emprendedor eficaz. (2020). La resiliencia. https://m.facebook.com/ emprendedoreficaz/videos/3438518422834561/?refsrc=http \%3A\%2F\%2Fwww.google.com\%2F\&_rdr

Fernández, A. M. (2009). La investigación social. Trillas.

Forbes (1 de agosto de 2019). México, el segundo país más feliz del mundo: Happy Planet Index. https://www.forbes.com.mx/ mexico-el-segundo-pais-mas-feliz-del-mundo-happy-planet-index/

Frankl, V. (2003). El hombre en busca de sentido. Herder.

Fuster, D. E. (2019). Investigación cualitativa: Método fenomenológico hermenéutico. Propósitos y representaciones, 7(1), 201-229. https://doi.org/10.20511/pyr2019.v7n1.267

Glaser, B. y Strauss, A. (1967). The discovery of grounded theory. Aldine. Grané, J. y Forés, A. (2012). Introducción: vocabularios de esperanza. La generación de posibilidades. En A. Forés y J. Grané (Eds.), La resiliencia en entornos socioeducativos (pp. 7-19). Narcea.

Gubern, R. (2012). La etnografía. Siglo XXI Editores.

Jáuregui, E. y Fernández, J. (2012). El humor y la resiliencia. En A. Forés y J. Grané (Eds.), La resiliencia en entornos socioeducativos (pp. 57-81). Narcea. 
Lazarus, R. y Folkman, S. (1986). Estrés y procesos cognitivos. Martínez Roca.

Levine, P. y Frederick, A. (1996). Curar el trauma. Urano.

Manrique, C. y Vidal, A. (2006). Estilos y estrategias de afrontamiento en adolescentes. Revista de Psiquiatría y Salud Mental, 7(1), 33-39. https://www.mdp.edu.ar/cssalud/deptoterapia/archivos/Psicologia_General_SEMINARIO/ESTILOS_Y_ESTRATEGIAS_DE_AFRONTAMIENTO_en_adolescencia.pdf

Martínez, E. (2013). Crisis, crecimiento y despertar. Desclée De Brouwer.

Masdemx. (2020). Covid a la mexicana: el ingenio nacional frente a la pandemia. https://masdemx.com/2020/06/covid-a-lamexicana-ingenio-nacional-pandemia/

Morán, M. C., Landero, R., y González, M. (2010). COPE 28: un análisis psicométrico de la versión en español del BriefCOPE. Universitas Psychologica, 9(2), 545-550. https://doi.org/10.11144/ javeriana.upsy9-2.capv

Morán, M. C., Finez, M. J., Menezes, E., Pérez, M. C., Urchaga, J., y Vallejo, G. (2019). Estrategias de afrontamiento que predicen mayor resiliencia. International Journal of Developmental and Educational Psychology, 4(1), 1-7. https://doi. org/10.17060/ijodaep.2019.n1.v4.1542

Organización Panamericana de la Salud, OPS. (1 de septiembre de 2020). Resiliencia en tiempos de pandemia. https://www. paho.org/es/documentos/resiliencia-tiempos-pandemia

O'Hanton, B. (2005). Crecer a partir de la crisis. Paidós.

Real Academia Española, RAE. (s.f). Resiliencia. En Diccionario de la lengua española. https://dle.rae.es/resiliencia

Redacción El Economista (24 de noviembre de 2020). México es el peor país para vivir en tiempos de COVID-19; con la tasa de mortalidad más alta de 53 países. El Economista. https://www. eleconomista.com.mx/politica/Por-que-Mexico-es-el-peorpais-para-vivir-en-tiempos-de-Covid-19-20201124-0097. html

Román, F., Forés, A., Calandril, I., Gautreaux, R., Antúnez, A., Ordheil, D., Calle, L., Poenitz, V., Correa, K., Torresi, S., Barceló, E., Conejo, M., Allegri, R., y Ponnet, V. (2020). Resiliencia de docentes en distanciamiento social preventivo obligatorio 
durante la pandemia de COVID-19. Journal of Neuroeducation, 1(1), 76-87. https://revistes.ub.edu/index.php/joned/ article/view/31727

Sandín, B., Valiente, R., García-Escalera, J., y Chorot, P. (2020). Impacto psicológico de la pandemia de COVID-19: efectos negativos y positivos en población española asociados al periodo de confinamiento nacional. Revista de Psicopatología y Psicología Clínica, 25(1), 1-22. https://doi.org/10.5944/ rppc. 27569

Schütz, A. (2008). El problema de la realidad social. Amorrortu.

Seligman, M. (2011). La auténtica felicidad. Zeta.

Seligman, M. (2014). Florecer. La nueva psicología positiva y la búsqueda del bienestar. Océano.

Simmel, G. (2010). El conflicto. Sociología del antagonismo. Sequitur.

Stake, R. (1994). Case studies. En N. Denzwhytein e Y. Lincoln (Eds.), Handbook of Qualitative Research (pp.236-245). Sage Publications.

Strauss, A. L. y Corbin, J. (2002). Bases de la investigación cualitativa. Técnicas y procedimientos para desarrollar la teoría fundamentada. Universidad de Antioquia.

Vanistendael, S. (2010). La resiliencia en lo cotidiano. En M. Manciaux (Comp.), La resiliencia: resistir y rehacerse (pp. 227-236). Gedisa.

Valles, M. (1997). Técnicas cualitativas de investigación social. Reflexión metodológica y práctica profesional. Síntesis.

Vera, B., Carbelo, B., y Vecina, M. L. (2006). La experiencia traumática desde la psicología positiva: resiliencia y crecimiento postraumático. Papeles del Psicólogo, 27(1), 40-49. https://dialnet.unirioja.es/servlet/articulo? codigo $=1417558 \&$ orden $=69$ 423\&info=link

Verd, J. M. y Lozares, M. (2016). Introducción a la investigación cualitativa. Fases, métodos y técnicas. Síntesis.

Yin, R. (1981). The case study crisis: Some answers. Administrative ScienceQuarterly, 26(1),58-65.https://doi.org/10.2307/2392599 